\title{
LETTER
}

\section{Response to: Important Considerations When Determining the Cost-effectiveness of Viscosupplements in the Treatment of Knee Osteoarthritis}

Jeffrey Rosen · Parag Sancheti $\cdot$ Anke Fierlinger $\cdot$ Faizan Niazi ·

Herman Johal $\cdot$ Asheesh Bedi

Received: September 29, 2016 / Published online: October 24, 2016

(C) The Author(s) 2016. This article is published with open access at Springerlink.com

We appreciate the feedback provided, and would like to address the highlighted concerns. The authors suggest that the included studies represent a small sample of the available literature. The studies included in our review were selected in a systematic and unbiased manner using comprehensive search of the published literature and pre-defined eligibility criteria. We do acknowledge that

J. Rosen ( $\square)$

Department of Orthopaedics and Rehabilitation, New York Presbyterian Queens, New York, USA e-mail: rosenje@nyp.org

J. Rosen

Department of Orthopaedic Surgery and Rehabilitation, Weill Medical College of Cornell University, New York, USA

P. Sancheti

Sancheti Institute for Orthopaedics and

Rehabilitation, Pune, Maharashtra, India

A. Fierlinger · F. Niazi

Ferring Pharmaceuticals Inc., Parsippany, NJ, USA

H. Johal

Division of Orthopaedics, Department of Surgery, Centre for Evidence-Based Orthopaedics, McMaster University, Hamilton, ON, USA

A. Bedi

Department of Orthopaedic Surgery, University of Michigan, Ann Arbor, MI, USA this economic analysis, like many others, is limited by the available data [1-4]. Many cost-effectiveness analyses use data from a single primary investigation, or combine cost an efficacy data from several identified studies, which is similar to our approach [2, 4-6].

As suggested by the authors, we accounted for the number of injections in our costing of each product. Despite this, the assumption that the authors of the editorial have made in their calculations assumes that all products have comparable efficacy, which is not accurate. Cost-effectiveness analyses consider differences in both cost and effectiveness. Assuming that the effectiveness is comparable is a cost-minimalization analysis, which is not appropriate when there are differences in both cost and effectiveness among the therapies compared. Utility scores derived from our included studies [7-11], as well as recent meta-analyses [12, 13], demonstrate considerable differences in efficacy that have been suggested to be due to product characteristic differences, such as molecular weight and production process. For this reason, we do not believe the authors' calculations looking strictly at product costs is 
an accurate depiction of the cost-effectiveness of the various hyaluronic acid products.

The authors of the editorial have provided detailed calculations comparing the cost differences between Synvisc-One and Euflexxa to demonstrate the missing information for Synvisc-One from our analysis. While this comparison suggests a cost savings with Synvisc-One over Euflexxa, it does not provide a complete picture, as utility data, and other costing data, are not considered. As mentioned above, in cost-effectiveness analyses, both cost and outcomes need to be included. For this reason, Synvisc-One was not eligible for inclusion in our analysis. If future investigations provide sufficient data to determine utility score improvements following the use of Synvisc-One, there would be sufficient information to include this product in an update of our analysis. To continue on this point, our analysis does not dispute that Supartz and Hyalgan are a less expensive option than Euflexxa; however, as stated above, the calculation you have provided does not consider the "effectiveness" portion of the cost-effectiveness analysis. The incremental cost-effectiveness ratio (ICER) values demonstrate the cost of additional efficacy provided by Euflexxa; as although Hyalgan and Supartz are less expensive, they also have demonstrated smaller QALY improvement estimates than Euflexxa.

We aimed to include as many comparators as reasonably possible to have comparable utility data. We were transparent in our methods when describing that the Euflexxa utility scores were obtained from a previous cost-effectiveness analysis conducted on the Altman trial. We do not believe that the utility scores extrapolated from the Hatoum study are substantially different from the other products; for example, Euflexxa and Synvisc were shown to have similar baseline values differing by 0.079 QALY. Despite us believing that the utility scores from the Hatoum study provided comparable results to the other studies, we conducted utility score sensitivity analyses to address the potential variability that you have highlighted. All results were calculated multiple times under a number of different sensitivity analysis scenarios to provide a more robust depiction of the results of our analysis.

There is always uncertainty regarding heterogeneity whenever multiple studies are compared, as stated by the authors of the editorial. This is an inherent limitation in not only our cost-effectiveness analysis, but in systematic reviews and meta-analyses as well. To account for the potential differences in utility scores as a result of study methodology heterogeneity, sensitivity analyses were conducted as a measure of ensuring that we considered potential differences from the utility score point estimates derived from the included studies. The authors are correct in stating that the inclusion of HRQoL measures within clinical trials would aid in conducting future cost-effectiveness analyses, as future authors would not require the data conversions used in our study to derive utility scores. Unfortunately, studies of IA-HA use for knee OA have not typically adopted this approach, which, therefore, makes our approach an appropriate alternative that is well documented and utilized in cost-effective analyses [14, 15].

We agree there are a very large number of indirect costs that could be considered when comparing products; however, it is often difficult to accurately estimate the differences in these costs within each group. While we aimed to address as many factors as possible, we also ensured to use a conservative and broad sensitivity analysis of costs to ensure that any 
potential real-world cost differences may be accounted for.

We appreciate the critical review of our work, and think that the author has brought up many important points. We agree and welcome future investigations to aid in effort to assist patients, physicians, and healthcare systems in choosing the best care for their patients with OA of the knee. We would like to thank the authors of the editorial for providing their feedback on our article.

\section{ACKNOWLEDGMENTS}

Medical writing assistance was provided by Global Research Solutions Inc., funded by Ferring Pharmaceuticals.

Disclosures. Jeffrey Rosen Serves on the Advisory Board for Ferring Pharmaceuticals Inc. Anke Fierlinger is a paid employee of Ferring Pharmaceuticals Inc. Faizan Niazi is a paid employee of Ferring Pharmaceuticals Inc. Asheesh Bedi is a consultant for Arthrex, Inc., and stock/stock options with A3 Surgical. Parag Sancheti and Herman Johal have nothing to disclose.

Open Access. This article is distributed under the terms of the Creative Commons Attribution-NonCommercial 4.0 International License (http://creativecommons.org/licenses/ by-nc/4.0/), which permits any noncommercial use, distribution, and reproduction in any medium, provided you give appropriate credit to the original author(s) and the source, provide a link to the Creative Commons license, and indicate if changes were made.

\section{REFERENCES}

1. Bozic KJ, Morshed S, Silverstein MD, Rubash HE, Kahn JG. Use of cost-effectiveness analysis to evaluate new technologies in orthopaedics-the case of alternative bearing surfaces in total hip arthroplasty. J Bone Jt Surg Am Vol. 2006;88A(4):706-14.

2. Lubowitz JH, Appleby D. Cost-effectiveness analysis of the most common orthopaedic surgery procedures: knee arthroscopy and knee anterior cruciate ligament reconstruction. Arthroscopy. 2011;27(10):1317-22.

3. Brauer CA, Neumann PJ, Rosen AB. Trends in cost effectiveness analyses in orthopaedic surgery. Clin Orthop Relat Res. 2007;457:42-8.

4. Clegg A, Colquitt J, Sidhu M, Royle P, Walker A. Clinical and cost effectiveness of surgery for morbid obesity: a systematic review and economic evaluation. Int J Obesity. 2003;27(10):1167-77.

5. Group UPDS. Cost effectiveness analysis of improved blood pressure control in hypertensive patients with type 2 diabetes: UKPDS 40. UK Prospective Diabetes Study Group. BMJ. 1998;317(7160):720-6.

6. Hatoum HT, Fierlinger AL, Lin SJ, Altman RD. Cost-effectiveness analysis of intra-articular injections of a high molecular weight bioengineered hyaluronic acid for the treatment of osteoarthritis knee pain. J Med Econ. 2014;17(5):326-37.

7. Karlsson J, Sjogren LS, Lohmander LS. Comparison of two hyaluronan drugs and placebo in patients with knee osteoarthritis. A controlled, randomized, double-blind, parallel-design multicentre study. Rheumatology (Oxford, England). 2002;41(11):1240-1248.

8. Altman RD, Akermark C, Beaulieu AD, Schnitzer T. Efficacy and safety of a single intra-articular injection of non-animal stabilized hyaluronic acid (NASHA) in patients with osteoarthritis of the knee. Osteoarthr Cartil. 2004;12(8):642-9.

9. DeCaria JE, Montero-Odasso M, Wolfe D, Chesworth BM, Petrella RJ. The effect of intra-articular hyaluronic acid treatment on gait velocity in older knee osteoarthritis patients: a randomized, controlled study. Arch Gerontol Geriatr. 2012;55(2):310-5. 
10. Day R, Brooks P, Conaghan PG, Petersen M. A double blind, randomized, multicenter, parallel group study of the effectiveness and tolerance of intraarticular hyaluronan in osteoarthritis of the knee. J Rheumatol. 2004;31(4):775-82.

11. Altman RD, Rosen JE, Bloch DA, Hatoum HT, Korner P. A double-blind, randomized, saline-controlled study of the efficacy and safety of EUFLEXXA for treatment of painful osteoarthritis of the knee, with an open-label safety extension (the FLEXX trial). Semin Arthritis Rheum. 2009;39(1):1-9.

12. Altman RD, Bedi A, Karlsson J, Sancheti P, Schemitsch E. Product differences in intra-articular hyaluronic acids for osteoarthritis of the knee. Am J Sports Med. 2016;44(8):2158-65. doi:10.1177/ 0363546515609599.
13. Rutjes AW, Juni P, da Costa BR, Trelle S, Nuesch E, Reichenbach S. Viscosupplementation for osteoarthritis of the knee: a systematic review and meta-analysis. Ann Intern Med. 2012;157(3):180-91.

14. Grootendorst P, Marshall D, Pericak D, Bellamy N, Feeny D, Torrance GW. A model to estimate health utilities index mark 3 utility scores from WOMAC index scores in patients with osteoarthritis of the knee. J Rheumatol. 2007;34(3):534-42.

15. Marshall D, Pericak D, Grootendorst $\mathrm{P}$, et al. Validation of a prediction model to estimate health utilities index Mark 3 utility scores from WOMAC index scores in patients with osteoarthritis of the hip. Value Health. 2008;11(3):470-7. 